Francisco Javier Tardío Gastón

Badajoz

\title{
LITERATURA REGIONALISTA EN EXTREMADURA: PRIMER TERCIO DEL SIGLO XX
}

Palabras clave: Extremadura, literatura regionalista, castúo, autores extremeños

\section{Introducción}

Hace aproximadamente dos meses que Javier Cercas visitó el centro donde trabajo para charlar con los estudiantes sobre literatura. A lo largo de su intervención, tras ser preguntado por sus preferencias en cuanto a autores extremeños se refiere, vino a decir, o así lo intuí yo, que en realidad no existe una literatura extremeña per se, «aquella que se escribe en Extremadura o por extremeños» (Sáez, Lama, 2003).

Esta reflexión trajo a mi memoria un artículo que leí no hace mucho tiempo y en cuyas líneas se pone en tela de juicio la idea de un dialecto extremeño, sin que ello suponga una falta de interés por el estudio de las distintas hablas que se dan en la ya mencionada región. Generalizando podemos decir que el extremeño no se escribe, y cuando así sucede, reproduce con palabras el plano fonético. Es decir, se intenta escribir como se habla.

A lo largo de los primeros compases del siglo XX, autores de la región, entre los que destacan Luis Chamizo y Gabriel y Galán, plasmaron en sus escritos ese dialecto castúo tan particular.

Hay muchos críticos que piensan que no podemos considerar como dialecto a algo que es minoritario porque no representa a la mayor parte de Extremadura y porque en él no se sienten identificados la mayoría de sus habitantes. No me detendré en una análisis pretencioso que debata si la lengua usada por esos autores pueda ser considerada un dialecto. Sin embargo, no podemos obviar la existencia de una serie de circunstancias sociales, culturales, políticas y literarias que se dieron cita en un periodo concreto de la historia de Extremadura y que dentro de un peculiar contexto regionalista dieron lugar a lo que hoy conocemos como literatura regionalista extremeña. Esas circunstancias y ese contexto literario es lo que se pretende analizar en el artículo. Intrahistoria, como diría Unamuno.

\section{Contexto histórico}

Asistimos a la internacionalización de la economía y al imperialismo como trasfondo de los primeros pasos del siglo XX donde los estados más avanzados se posicionan para dominar y repartirse países menos desarrollados. En el contexto europeo podemos decir que la estabilidad caracterizó la sociedad de la época hasta que diversas cuestiones conectadas con aspiraciones a la supremacía mundial y con la exaltación de sentimientos nacionalistas provocaron tensiones en las relaciones internacionales que desembocaron 
en una guerra devastadora con terribles efectos traumáticos en las conciencias de los hombres.

En España, el despuntar del siglo mostraba un cuadro rural con abundante mano de obra injustamente remunerada, lo que provocaría conflictos, revueltas sociales y éxodo del campo a la urbe. La industria carecía del deseado desarrollo y su sector estaba en manos del poder extranjero. Los pocos focos de industrialización se localizaban lejos del poder centralista, es decir, Cataluña y País Vasco. Curiosamente, áreas donde se desarrollaría una pudiente literatura regionalista, cimentada en un enraizado nacionalismo, que bien se diferenciaría de la literatura regionalista extremeña forjada en un contexto mucho más conservador como veremos a lo largo del artículo.

El espectro nacional presentaba una clara bicefalia entre lo liberal y lo conservador. Mientras la unión de los bien avenidos terratenientes y grandes financieros creaba la oligarquía, el socialismo y el anarquismo tomaba posiciones desde el movimiento obrero y la intelectualidad que añoraba y pedía una transformación social y cultural. El atraso económico y social sembró el terreno para la corrupción del sistema parlamentario que no veía diferencias básicas en gobiernos liberales o conservadores. Esta inestabilidad unida a las convulsiones sociales pincelaron la sociedad de principios de siglo que avanzaba sin remedio a un choque de fuerzas que acabaría con las dos Españas enfrentadas entre sí en la guerra civil.

En Extremadura destacaban tres bloques que aglutinaban el poder político tanto dentro como fuera de la región: los oligarcas, los caciques y gobernación civil, que hacía las veces de hilo conductor entre ellos. Poco podían hacer las organizaciones sociales existentes para evitar la evidente marginalidad en que vivía la gran mayoría de la población extremeña. Digamos que para la minoría pudiente el sol calentaba a la sombra de una parra, mientras que para los sufridos labriegos era un astro abrasador que curtía ferozmente su piel en las eras veraniegas.

Profundo desequilibrio podría ser una buena definición de la situación que se vivía en el ámbito agrario, ya que una minoría oligarca era dueña de la mayor parte de la riqueza rústica. Las consecuencias eran la proliferación del latifundio y la pérdida patrimonial de dehesas boyales destinadas al pastoreo del ganado de los vecinos. Ni que decir tiene que todo ello fue caldo de cultivo para el inevitable deterioro de la camaradería social.

Aunque se produjo un crecimiento demográfico, Extremadura siempre fue una región poco poblada en comparación a la media nacional y los estatus sociales repetían el canon económico, es decir, mundo agrario y rural con profundos desequilibrios patrimoniales. Siempre la misma cantinela: poderosa oligarquía terrateniente frente a una gran masa de humildes campesinos que sobrevivían en precarias condiciones.

\section{Contexto cultural}

El primer tercio del siglo XX fue una etapa rica y prolífica en los campos artístico y cultural. Surgieron multitud de movimientos en un periodo de tiempo relativamente 
pequeño que además buscaban romper desde la experimentación con el arte anterior: expresionismo, cubismo, dadaísmo, surrealismo... Eran las vanguardias.

En España, ese anhelo por crear un arte nuevo, abierto y liberal tuvo en Cataluña, gracias a su experiencia comercial y a una buena infraestructura, un claro exponente: el Modernismo. Se planteaba una doble manifestación de la realidad que se apoyaba en el deseo de expresar conjuntamente la prosperidad de una época y el sentimiento nacionalista tan arraigado en la cultura catalana.

Cuando hablamos de regionalismo nos referimos, según Viola Morato (2003), a un fenómeno complejo en el que se mezclan postulados políticos y manifestaciones culturales. Las literaturas en lenguas distintas del castellano tenían su origen en el impulso que ya venía ejerciendo el nacionalismo romántico. Proliferaron publicaciones que defendían el alma autonómica, y Extremadura no fue una excepción: El Cantón Extremeño, La Revista de Extremadura, Revista del Centro de Estudios Extremeños o El Autonomista Extremeño.

Sin embargo, a diferencia de otras zonas peninsulares, en esta tierra de conquistadores, las ideas regionalistas presentaban tintes moderados que impregnaron la cultura y la literatura de la región desde el amor al terruño y el interés tanto por lo moral como por las costumbres. Con este panorama no es difícil entender que la recuperación del folclore local fue un hecho consumado cuyo pilar básico eran las tradiciones populares. A lo largo y ancho de toda la orografía extremeña nacieron sociedades, como El Folk-lore frexnense en Fregenal de la Sierra, con el fin de recopilar y estudiar el saber popular.

El yugo del catolicismo, receloso de cualquier innovación intelectual o ideológica, dejaba caer todo su peso sobre la sociedad extremeña abanderando una postura tradicional e impidiendo que las excepciones próximas a círculos más liberales calaran en el periodismo y en la literatura de la región. A pesar de todo ello surgió como modelo contestatario el Krausismo.

En España, este movimiento se definía como corriente intelectual que protestaba contra los valores establecidos y contra una sociedad dogmatizada que ignoraba los avances científicos. Profesaba la pasión por el saber, la fe en la razón, la importancia de la educación etc. En Extremadura con este movimiento mediante diversas publicaciones como La Crónica o Diario de Badajoz, se defendía una religiosidad racional, tolerante, respetuosa con otras creencias, la escuela laica, la educación femenina, un reformismo social, etc. Destaca la figura de Tomás Romero de Castilla y Peroso y su intento por armonizar krausismo y catolicismo.

Estos aires de desarrollo y avance, en Extremadura no eran más que una quimera, un barco a la deriva en un mar agitado por el analfabetismo; el 67\% en 1910. Faltaban escuelas, había graves deficiencias y carencias en los locales destinados a la enseñanza y el absentismo entre el alumnado era la tónica general. En tiempos de estraperlo en una familia pobre más valía ayudar en las tareas agrícolas que asistir a clase. Siguiendo la línea descendente, la educación secundaria llegaba al 0,1\% mientras que la educación superior era coto restringido para la élite económica y social. 


\section{Contexto literario}

A principios de siglo los escritores presentaban variadas actitudes a pesar de manifestar inquietudes comunes. Desde el desprecio por las convenciones persiguen la originalidad. De esta manera muchos críticos veían en el Modernismo una fuerza disgregadora y anárquica, rebelde ante la sociedad. Todo ello emparentaba en cierta manera esta corriente con la rebelión romántica.

El rechazo de la dinámica histórica y la implicación política en sus años de juventud hicieron que ciertos autores, los considerados pertenecientes a la Generación del 98, buscaran la austeridad, el espíritu de Castilla, la esencia de España. El hedor a muerte, dolor y decadencia está presente en muchas obras de la época. Esta insatisfacción con el mundo provocaría una angustia existencial que llevaría a los literatos a la búsqueda de lo trascendente superando lo aparente.

En Europa se sucedían vertiginosamente los movimientos vanguardistas que anhelaban la experimentación y el desarrollo de un arte nuevo reaccionando contra la sensibilidad romántica y portando la bandera del antisentimentalismo. Sus ecos llegaron a España cuando al mismo tiempo en nuestras fronteras se abría paso el novecentismo. Su desarrollo fue decisivo para el impulso inicial del grupo poético del 27 , que añadiría e integraría sus elementos en una poesía equilibrada entre la tradición y la vanguardia.

A modo de síntesis y como podemos observar, la literatura de esta época es tan compleja y variada como el contexto histórico y social en el cual se desarrolla. Quedémonos con la idea de regeneracionismo como herramienta para superar el desastre en el que se encontraba el país. Regeneracionismo que en literatura, una vez agotado el realismo, llegó con la poesía de Rubén Darío y los hermanos Machado, la manera de novelar de Unamuno o Baroja y el teatro renovador de Valle-Inclán.

En Extremadura este regeneracionismo, o reacción como indican Sáez Delgado y Lama (2003) en su libro, llegó en el último vagón doliente por la acusada ausencia de espacios culturales. A pesar de todo ello no podemos olvidar que su llegada traía cogida de la mano la inquietud que en esos años se erguía.

Herederos del realismo conservador del XIX y del regionalismo anterior que se desarrolló en regiones como Galicia o Cataluña, los autores regionalistas personalizaban casi por completo el marco literario de Extremadura. Con Gabriel y Galán como maestro y guía, idealizaban la vida rural en sus creaciones literarias presentando el desarrollo social como peligro amenazante para la pervivencia de lo popular, de lo castúo, de la raza extremeña. En su literatura, teniendo presente que una minoría oligarca y terrateniente era la depositaria de la cultura y la palabra, no tenían cabida otros temas que no sintonizaran con el conservadurismo en cuanto a los temas, el estilo y la intención. Sin embargo, fue muy bien acogida, ha perdurado como herencia estética y hoy día sigue siendo seña de identidad para muchos extremeños. Todo ello quizás venga provocado por el vacío de elementos regionales con los que sentirnos identificados en relación a una pertenencia histórica y social, y esta expresión artística ayude a ese propósito.

El buque insignia del regionalismo literario es Luis Chamizo, que acabó consagrándose, gracias al ritmo y prosodia de sus versos y a la versión literaria de una supuesta 
habla regional utilizada en El miajón de los castúos, como el poeta por antonomasia de la región.

La prosa de la época reflejaba el sentimiento conservador de una sociedad aferrada a sus costumbres que se negaba a cambiar, o no podía hacerlo debido a que las clases más poderosas lo impedían, para de esa manera perpetuarse en la cúspide de la pirámide social, y que únicamente abogaba por algunas reformas que acabasen con las injusticias más evidentes desde un cierto catolicismo social de la época. En este contexto literario el representante más destacado fue el narrador y periodista Antonio Reyes Huertas. Sin embargo, el más complejo y moderno de los regionalistas fue Francisco Valdés que a pesar de su regionalismo basculante hacia postulados fascistas supo y cultivó una prosa novecentista.

Pero si hay un autor que con su obra denunciara con especial énfasis la situación social en la Extremadura de la época, y especialmente la vida rural, ese fue Felipe Trigo. Cercano al regeneracionismo y al 98 escribió desde el prisma naturalista, a pesar de publicar Jarrapellejos en pleno apogeo novecentista, que ya estaba superado en la época. Este aparente anacronismo literario venía motivado por el recelo y la tardanza con la que llegan a Extremadura los nuevos modelos estéticos.

De la mano en el tiempo, el modernismo expandía su influencia, y matices de su expresión más superficial inyectaron la literatura de autores que permanecerían en la ola modernista durante un lago periodo de tiempo. Por el contrario, las vanguardias pasaron de largo en la región mientras que en otras partes de España el 27 y sus manifiestos florecían con notable éxito.

Así pues, autores como Luis Chamizo, Gabriel y Galán, Reyes Huertas o Francisco Valdés, en tiempos en los que naciones y pueblos reivindicaban una propia identidad, en esta época de nacionalismos, trataban de reproducir desde la tradición realista y el costumbrismo la esencia de la región a la que espiritualmente pertenecían. De esta manera, en su afán por descubrir lo propio del pueblo extremeño parieron la literatura regionalista extremeña bañada de nostalgia y melancolía por el recuerdo de tiempos pasados que les llevó a inventar un campo, su mundo, pleno de armonía y felicidad. Un mundo idealizado que se transmitía haciendo uso de un supuesto dialecto extremeño.

Eran chiquirrininos dambos hermanos...

¡Qué tiempo aquel!...Roaba la vida güena,

cristiana y labraora, mansa y jorzúa,

con el roar pausao de las carretas. (Chamizo, 1985)

\subsection{Gabriel y Galán}

Al contrario que Vicente Medina, autor murciano que representó un regionalismo radical y revolucionario, Gabriel y Galán era más tradicional y conservador. Uno de sus logros fue dignificar con su poesía formas dialectales que hasta entonces se empleaban exclusivamente con fines burlescos representando temas meramente jocosos y que ahora alcanzaban una esfera más sentimental o incluso trágica. Alternó el uso del castellano con el dialecto extremeño. 
Considerado como autor adoptado por haber nacido en Salamanca. Su madre era culta, dedicada a la familia y a escribir poesía, y su padre labrador, por lo que el contacto con la tierra resultó inevitable para este poeta rural. Ejerciendo como maestro se casó con una joven extremeña y siguiendo sus aficiones dimitió del cargo y vivió consagrado a la labranza y al cuidado de su familia convirtiéndose en un acaudalado terrateniente.

El soporte ideológico del poeta es la constante búsqueda de estabilidad social que ya había conocido desde su niñez y que giraba en torno a una férrea jerarquización tradicional anclada en principios cristianos. Sin embargo, no permanece absorto ante el sufrimiento ya que esa misma fe cristiana hizo que denunciara injusticias y que menospreciara la avaricia, la explotación y el egoísmo. Era un hombre que aunque estaba inserto en los intereses de clase sabía el significado de la palabra compartir y rehuía de quienes vivían gracias al trabajo ajeno.

¡Vida que vive asida,

sabia sorbiendo, de la ajena vida,

duerma en el polvo en criminal sosiego!

¡Rama seca o podrida

perezca por el hacha o por el fuego! (Gabriel y Galán, 1996)

Esta doble vertiente no pasó inadvertida para nadie, y así, desde el principio, encontró por un lado el apoyo de la jerarquía eclesiástica que veía en su poética una útil herramienta para afianzar el orden social mientras que intelectuales como Unamuno expresaban su simpatía hacia el autor por considerar sus versos un soporte intelectual con el que embestir contra el Modernismo y los nuevos aires poéticos. Tal y como indica Pecellín (1981): «el casticismo costumbrista que transmite estaba bien lejos de los aires modernistas». Sin embargo, en realidad, su postura ante el Modernismo fue mucho más moderada.

En su temática, el paisaje es un elemento relevante cargado de sensaciones e impresionismo que lo aproximan al «98». Si hay algún lugar donde encontrar armonía y equilibrio, es en el campo y en el ambiente religioso que junto a su patriotismo lo alejan a la vez de la Generación. Resalta lo rural, y en sus creaciones, por encima del elemento paisajístico, destacan los personajes reales, como el vaquerillo o el gañán, que habitaban el mundo campesino.

Poeta social, desde el paternalismo cristiano que acepta el orden establecido, la autenticidad de la vida aldeana y la invitación al trabajo, lamenta la desdicha de los más desfavorecidos. Además, siempre se mostró ajeno a las innovaciones que marcaban el camino de la poesía española, noventaiochistas y modernistas, reprochando el uso de una estética que venía de «fuera».

No es mi musa la musa cortesana de palabra de miel y áureo ropaje que quema incienso a la grandeza humana; 
es la ruda aldeana

que va vestida con honesto traje,

cantando la virtud en el lenguaje

que le enseñó naturaleza sana. (Gabriel y Galán, 1996)

\subsection{Antonio Reyes Huertas}

Nacido en Campanario, en el seno de una familia modesta y profundamente católica, siempre conservó el sentir religioso, la tradición y el ámbito clerical influido tanto por sus progenitores como por los estudios filosóficos y teológicos que realizó en el seminario. Posteriormente abandonaría el centro e iniciaría una intensa labor periodística en no pocos periódicos y revistas como El Noticiero Extremeño, Acción Social, Pueblo Extremeño o La Defensa. Esta labor la compaginaría con la literatura a través de artículos, poesías, novela, etc.

Su fidelidad, tanto a su formación familiar como a la recibida en el Seminario, hizo que fuera hombre de confianza para la jerarquía eclesiástica que incluso llegó a financiar ciertos proyectos del escritor cuyas posibilidades económicas no eran precisamente pingües. Se enfrascó en el debate ideológico de la época y junto con Francisco Valdés y otros amigos publicaría la revista Tierra Extremeña a fin de neutralizar la propaganda socialista. Su prisma vital siempre giró en torno a la burguesía aunque consideraba el absentismo y el caciquismo como lacras social y económica que minaban las libertades en la región. Sencillo y tolerante, fue una persona destacadísima en la cultura extremeña en la primera mitad de siglo.

Aunque dio sus primeros pasos en la literatura a través de la poesía su aportación de mayor interés la podemos encontrar en la narrativa. Insigne exponente del realismo extremeño en el siglo XX lo incluimos en el regionalismo por sus relatos costumbristas, idealizantes y nostálgicos donde aparece Extremadura como protagonista. De todos ellos, la novela La Sangre de la Raza (1919), es la que tuvo una gran acogida de público tanto en la propia región como fuera de ella. Tal aceptación no se correspondería con la crítica, ante la cual siempre se sintió un incomprendido.

Alejado de las formas tremendistas concibe la novela como lugar en el que se dan cita lo verosímil y lo ordinario de las estampas extremeñas. De esta manera, sus obras son un buen filón para la antropología ya que recogen infinidad de manifestaciones folclóricas como la matanza ${ }^{1}$, la encamisá ${ }^{2}$ o la candelaria ${ }^{3}$, además de excelentes referencias sobre la gastronomía local.

$\mathrm{Su}$ tema preferido es el enfrentamiento entre el campo y la ciudad, lo rural y lo urbano, saliendo vencedor éste primero. Disfrutaba de la tranquilidad de la campiña, de lo natural, lo sencillo, y en todo ello se recrea para ser testigo transmisor de los rincones

Faena de matar los cerdos con el fin de aprovecharlos para el consumo humano.

2 Procesión nocturna a caballo en Torrejoncillo donde los jinetes, cubiertos con una sábana, portan la noche del siete de diciembre un estantarde de la Virgen Inmaculada al son de cantos, vítores y disparos.

3 Candelas que se celebran la noche del 2 de febrero en honor al santo Blás y alrededor de las cuales la gente se reúne para degustar productos típicos de la región. 
más rurales. Las tesis que se repetían una y otra vez eran el absentismo como gran mal de Extremadura, la política corrupta e inútil y el caciquismo. Dentro de su faceta narradora se ha destacado por la gran brillantez con la que describe los campos y los pueblos extremeños. Estas descripciones abundan y vuelan a vista de pájaro sobre dehesas, heladas invernales, el sopor veraniego, la siembra, etc.

El paisaje humano, al igual que en Gabriel y Galán, es básico para el escritor, y no olvida en sus páginas presentar a hidalgos arruinados superados por los nuevos tiempos, ricos propietarios, profesionales acomodados como el boticario, el maestro o el médico, y el pueblo llano. Todo se conglomeraba a través de un hilo conductor: una historia de amor. Un triángulo amoroso en el que el rico joven se enfrenta a un doble amor. Por un lado la mujer de distinta clase social o mujer casada, aspecto frívolo, y por otro la joven acomodada, serena y aceptada socialmente. Gustaba mantener la indecisión hasta el final que casi siempre era el matrimonio que perpetuaba la relación entre clases parejas.

Siempre mantuvo el vínculo al terruño y aunque tras la guerra marchó a Madrid nunco rompió los nudos que lo ataban a Extremadura en cuyas tierras pasaba largas temporadas cada año y donde murió un 10 de agosto de 1952.

\subsection{Francisco Valdés}

Caso trágico y contradictorio por ser sin duda el mejor prosista, pero al mismo tiempo ser consciente de la falta de horizonte y destino incierto que tenía el camino elegido: el regionalismo extremeño.

Nació en Don Benito en 1892, hijo de grandes propietarios rurales pudo salir del contexto provinciano y estudió en Madrid donde pudo contactar con novecentistas y autores del 98. En la Residencia de Estudiantes coincidió con Juan Ramón Jiménez que le animaría a escribir. Así pues, del 98 heredó el concepto de intrahistoria que tanto influiría en sus posteriores creaciones en prosa. Fue un gran viajero tanto por España como por tierras europeas. Todo ello le proporcionó una gran cultura cimentada en la lectura de los clásicos y un espíritu culto y refinado, extraño en su ambiente rural.

Paradójicamente, al regresar a Extremadura toda este ambiente literario modernista, innovador, toda la esfera estética y el mundo abierto que representaba la generación del 27 fue dando paso a una rabiosa melancolía dentro de la tradición temática del regionalismo literario extremeño. El autor que a nosotros nos interesa no es el cosmopolita viajero sino el nostálgico regionalista que escribió Ocho estampas extremeñas con su marco. Esa melancolía desgarrada y desesperanzada lo acercaró a posturas conservadoras muy extremistas cayendo dentro del más ortodoxo tradicionalismo político y religioso que acabaría con un enfrentamiento directo a la izquierda.

En esta metamorfosis abandonó los ámbitos universitario y artístico y regresó al pueblo teñido de contradicciones que mezclaban por un lado el aprecio por el entorno y por otro el desaliento ante las convulsiones sociales que se estaban viviendo. Ni que decir tiene que toda esa experiencia pinceló la obra de Valdés. 
Si nos sumergimos en sus páginas encontramos el paisaje humano compuesto por hombres y mujeres con sus luchas diarias, deseos e íntimas tragedias. Aparece gente humilde: campanera despedida, labradores, gañanes, un buhonero, ancianos, etc. Frente la felicidad y complacencia de Reyes Huertas, las Estampas de Valdés presentan a perdedores enfrentados a problemas imposibles de resolver como unos labradores ante una sequía, un joven pescador traicionado por una mujer, un viejo carpintero jubilado y sin patrimonio... Basculaba entre el amor a la tierra, sus gentes y la denuncia del abandono y postración.

Influido por los noventaichistas, con sus descripciones agrias e hirientes de la vida en el pueblo, y sin detenerse ante ninguna clase social, mostraba afecto por el extremeño noble y entregado pero lamentaba «la postración cultural, el fanatismo y la superstición, las lacras del caciquismo, la enfermedad y el hambre» (Viola Morato, 2003).

[...] No es la brasa del volcán quien ha destruido mis retamas, como esas del canto leopardino. Ha sido la lava del volcán de la codicia humana. El brazo destructor al servicio de la intención malvada. Llegaron de las villas inmediatas. Entre ellas, Magacela. En ese desborde incontenido de feroces cuadrillas insaciables, en pocos días, me arrasaron el retamal magnífico: orgullo comarcano, delicia de la vista, consuelo de mi vida. Juntas de hombres se llegaron a él, acometiéndole con las manos, con las hachas, con los picos, con los zachos. Quedó rasa y desnuda la tierra que le mantenía. No parecía la misma. Quedaron como testigos de la afrenta las viejas encinas, las charcas brunidas de azul rizado, los aguardos de la perdiz, la roja piedra guijeña. Quedó como campo de abandono y desolación lo que antes fuera alegría y abalorio de feria campesina. (Ocho estampas. Las retamas)

Valdés fue, como en el caso de Federico García Lorca, un ejemplo más del trágico destino que sesgó la vida de muchos intelectuales en una etapa en la que no tenían cabida posturas abiertas al diálogo y a la tolerancia.

Fue asesinado en Don Benito por los milicianos en 4 de septiembre de 1936.

\subsection{Luis Chamizo}

Nació en Guareña en 1894 y tuvo una buena formación académica gracias al esfuerzo de humilde pero emprendedor padre. Estudió en Servilla y Madrid para luego regresar a su pueblo natal. Durante se estancia en Madrid tomó contacto con el modernismo y publicó en algunas de sus revistas. Muchas de sus Poesías Castellanas reflejan la escuela de Rubén Darío.

Dormida avenida, remanso de vida, donde la virtud trenza en las guirnaldas de tus esmeraldas a la juventud. (Sonatina. Castellanas) 
Sus primeras composiciones las publica en el periódico La Semana de Don Benito que dirigía Francisco Valdés. En Extremadura abundaban por entonces los Juegos Flora$\operatorname{les}^{4}$, a los que concurrían muchos de nuestros poetas. Chamizo lo hizo, aunque sin mucho éxito, en Almendralejo con Los consejos del tío Perico, poema que ya tomaba la senda regionalista.

No me jimples, no me jimples, mocosina; no $t^{\prime}$ enfusques ni me fartes al respeto, no reguñas, Carnación, ni esparrataques esos ojos cuando yo te dé un consejo. (Consejos del tío Perico. El Miajón de los Castúos)

El miajón de los castúos es la obra más conocida del poeta, la que tuvo más éxito y la que en la actualidad sigue valiendo como carta de presentación para esta tierra en muchos círculos intelectuales. Para muchos es la más acertada «epopeya de la Extremadura rural, sufriente y cotidiana, con un inigualable molde racial, expresivo y paisajístico» (Pecellín Lancharro, 1981). Pero, ¿por qué ese título para estas Rapsodias Extremeñas? El término miajón hace referencia a la miga de pan, figuradamente refleja la entraña, la esencia de las cosas. Castúo es una palabra que no fue utilizada con anterioridad y con ella el autor presenta al extremeño auténtico, genuino, con talante regional. Así pues, con estas palabras Chamizo capta la esencia del espíritu y del alma de Extremadura. Presenta el subtítulo Rapsodias extremeñas en una clara referencia a la poesía homérica. Si analizamos sus poemas observamos que la atención central recae en lo cotidiano, como no podía se de otra manera en el regionalismo literario, pero hay cierta heroicidad en el modo de vivir de los personajes. Siguiendo la línea del regionalismo aborda el paisaje, la tierra de labranza, el amor, lo religioso y los problemas que había en la región. También, a pesar de su visión tradicional que manaba de la importante influencia familiar y de sus creencias religiosas, rechazó la oligarquía terrateniente y proclamaba a los cuatro vientos la necesidad de una reforma social y agraria que mejorara la situación del campesinado.

Al igual que hicimos con Gabriel y Galán podemos decir que Chamizo, aun teniendo una ideología más bien conservadora, no en vano sus mismos obreros durante la guerra civil lo escondieron de bandas incontroladas de milicianos con el fin de protegerlo, suerte que no corrió Francisco Valdés, opta a merecer la condición de poeta social. Irá en función de cómo queramos leer e interpretar algunas de sus poesías. Irrefutables son ciertos versos juveniles inclinados para con los más débiles

Son hombres que poblaban los abismos sagrados del hambre y la ignorancia, sedientos de ideal, hasta que con las uñas férreas de los arados y la cota de vellos de sus pechos honrados elevaron al trono la justicia social. (Mis polichinelas. Castellanas)

4 Concurso poético instituido por los trovadores en Provenza, y por don Juan I de Aragón en Cataluña, y el cual aún suele celebrarse en muchas partes, mantenido por varones ilustres y presidido por una reina de la fiesta, con premio de flores simbólicas para el poeta vencedor. 
Otra notable faceta del autor fue su incursión en el teatro mediante un drama rural enmarcado en el teatro poético y titulado Las brujas. Aunque el eje central es una desdichada historia de amor, la trama hace constantes guiños al folclore popular extremeño y sus costumbres con conjuros, brujerías y supersticiones de porqueros, pastores y zagales, vaqueros, mayorales...

Las obras más notables que hemos mencionado coincidieron en el tiempo con las vanguardias y la generación del 27. Sin embargo, se mantuvo al margen de esta renovación lírica y voluntariamente se refugió en el ámbito localista y agotado del regionalismo. Este acento regionalista lo robusteció dotando a sus personajes con el habla particular de ciertas áreas geográficas de la región.

Tras finalizar la guerra civil marchó a Madrid y alejado de Extremadura perdió la inspiración que con tanta facilidad encontraba en la dehesa. Allí permaneció hasta 1945, año en que murió el más tardío pero posiblemente el mejor exponente del regionalismo literario extremeño.

\section{Conclusión}

Posiblemente me haya dejado en el tintero algún que otro autor, pero creo que los que aquí se presentan son un fiel reflejo de lo que muchos consideran literatura regionalista extremeña. Una de las mil facetas que posee la literatura es sentar las bases de la razón de ser de la sociedad. En ellas tienen cabida lo cultural, lo social, lo político...Y a través de ellas los seres humanos buscamos la pertenencia a una manera de ser, de sentir, de sufrir, de vernos semejantes y diferentes a otros. Por todo ello, interpretamos como algo propio un país, una región, un pueblo, una familia. Eso mismo sintieron los autores extremeños en el primer tercio del siglo XX, y eso quisieron transmitir con sus obras. Nosotros lo aceptamos, lo asimilamos, lo hicimos nuestro, y ahora nos ayuda a vernos inmersos en el profundo sentir extremeño.

\section{BIBLIOGRAFÍA}

Chamizo, L. (1985): Obras Completas / Luis Chamizo. Edición de Antonio Viuda. Badajoz: Universitas, D.L.

Gabriel y Galán, J.M. (1996): Obras Completas. Badajoz: Universitas Editorial.

Pecellín Lancharro, M. (1981): Literatura en Extremadura, Tomo II. Badajoz: Biblioteca Básica Extremeña.

Sáez Delgado, L., Lama, M.A. (2003): Literatura en Extremadura, Siglo XX. Antología de textos. Badajoz: Del Oeste Ediciones.

Viola Morato, M.S. (2003): Medio siglo de Literatura en Extremadura (Del cambio de siglo a los años cincuenta). Badajoz: Diputación de Badajoz. 


\section{REGIONALISTIČNA KNJIŽEVNOST V EXTREMADURI: PRVA TRETJINA 20. STOLETJA}

Ključne besede: Extremadura, regionalistična književnost, castúo, avtorji iz Extremadure

Avtor članka želi seznaniti bralca s književnostjo, ki je sicer lokalno omejena in časovno precej minljiva, vseeno pa predstavlja verno podobo območja, oddaljenega od vsakršnega vpliva modernosti. Pri tem izhaja iz dileme, ki pod vprašaj postavlja pristnost regionalistične književnosti Extremadure, in analizira kulturne, zgodovinske in književne vidike Španije in Extremadure v prvi tretjini dvajsetega stoletja. Študija štirih avtorjev, Gabriela y Galána, Reyesa Huertasa, Francisca Valdésa in Luisa Chamiza, nam razkriva književna dela, ki jih označuje močan konservatizem, pa vendar krivice, ki so jih trpeli najbolj revni sloji kmečkega prebivalstva v Extremaduri, niso zamolčane. Njihova dela s kostumbristično in folkloristično tematiko, ki temelji na posebnem jeziku te pokrajine (el castúo), predstavljajo odlično književno dediščino. 